\title{
A utilização das TIC nos processos de formação continuada e o envolvimento dos professores em comunidades de prática
}

\section{ICT use in teacher training proceedings and the teachers' participation in practice communities}

\author{
Glauco Gomes de Menezes ${ }^{1}$
}

\begin{abstract}
RESUMO
Este artigo discute sobre o uso das Tecnologias de Informação e Comunicação (TIC) e levanta preocupações contemporâneas sobre o papel do professor da educação básica como um produtor de conhecimento. Este estudo tem como objetivo analisar a utilização das TIC como um artefato usado para mediar o processo de produção de conhecimento; também realiza uma pesquisa exploratória e qualitativa, por meio de análise documental, a fim de apresentar discussões sobre como os professores da Educação Básica do Estado do Paraná (Brasil), estão envolvidos no processo de produção, sistematização e divulgação do conteúdo educacional na Internet. Finalmente, apresenta algumas análises para relacionar as diferentes formas de participação do professor na formação de comunidades de prática dessa natureza.
\end{abstract}

Palavras-chave: saberes docentes; TIC; formação de professores; produção de conhecimento; educação continuada; comunidades de prática.

\begin{abstract}
This article discusses about the use of Information and Communication Technologies (ICTs) and raises contemporary concerns about the role of primary education teachers as knowledge producers. This study aims to analyze the use of ICTs as an artifact used to mediate the process of knowledge production; it also performs an exploratory and qualitative research,
\end{abstract}

1 Universidade Federal do Paraná (UFPR), Setor de Ciências Sociais Aplicadas. Av. Pref. Lothário Meissner, 632 - $2^{\circ}$ andar, Curitiba, Paraná, Brasil. CEP 80210-170. 
through documentary analysis, in order to present discussions about how the Elementary Education teachers of the Parana State (Brazil) are involved in the process of production, systematizing and publicizing the educational content in the Internet. Finally, it presents some studies to relate different forms of teachers' participation in the formation of practice communities of this nature.

Keywords: teacher knowledge; ICT; teacher education; knowledge production; continuing education; practice communities.

\section{Introdução}

Desde a década de 1980, o papel do professor como produtor de conhecimento vem sendo discutido a partir de diferentes perspectivas teóricas, entre as quais esta pesquisa prioriza três, a saber: o profissional reflexivo (SCHÖN, 1983, 2000); o professor prático-reflexivo (LISTON; ZEICHNER, 1991; ZEICHNER, 1993); o professor-investigador (STENHOUSE, 1998). Estes autores são convidados a um diálogo que busca debater a natureza do trabalho realizado pelos professores, enquanto profissionais, trazendo questões relacionadas à dissociação entre a atividade docente e a produção do conhecimento - enraizada na distinção entre a produção e transmissão - e a configuração da formação docente como pertencente "à ordem da prática".

Os estudos de Schön $(1983,2000)$ problematizam a importância da prática e dos processos reflexivos na atividade docente. Segundo este autor, o conhecimento-na-ação, a reflexão-na-ação e a reflexão-sobre-a-ação são elementos apontados como inerentes ao perfil do profissional reflexivo e, também, considerados como pertinentes às expectativas da formação pessoal e profissional do professor contemporâneo.

Posteriormente, estas teorias são adotadas por Liston e Zeichner (1991) e Zeichner (1993), que as discutem na perspectiva específica da atividade docente, em estudos que exploram as concepções de conhecimento dos professores, que, segundo os autores, caracterizam-se enquanto profissionais que não são valorizados por seus conhecimentos, sejam eles cotidianos ou constituídos.

Outro conceito que tem sido enfatizado nos debates sobre a formação de professores é o de professor-investigador (STENHOUSE, 1998), que considera a ideia da participação efetiva dos professores nos processos de pesquisa científica como necessária para a obtenção de melhores resultados na sua utilização em 
ambientes escolares. O autor representa uma posição mais avançada na compreensão de que os conhecimentos "da prática" necessitam ser examinados pelos próprios professores em ações de investigação, o que conduziu suas discussões e seus projetos para um esforço de aproximação entre os pesquisadores e os professores, aspecto relevante para a compreensão da natureza dos conhecimentos necessários aos docentes.

A problematização da natureza do conhecimento necessário à formação de professores no mundo contemporâneo foi acrescida, particularmente nas últimas décadas, de um novo elemento - a presença das TIC (Tecnologias de Informação e Comunicação). De início, as preocupações se voltavam mais especificamente para o uso dessas tecnologias pelos professores, para ensinar as novas gerações - estas já nascidas em um mundo marcado pela presença de recursos e linguagens decorrentes dos avanços tecnológicos. No entanto, ainda que essas questões permaneçam em pauta, hoje as TIC também se tornaram um caminho para a formação inicial e continuada de professores, em processos que são chamados genericamente de Educação a Distância - produzindo uma expansão significativa de cursos ofertados pela iniciativa privada e também pelas instituições públicas, o que abre novos campos de debate e investigação dentro do tema da formação docente.

Ao considerar o professor como o sujeito responsável pela produção dos saberes que caracterizam a função docente, a literatura pertinente apresenta algumas formas diferenciadas de compreender o que é e como pode ocorrer esse processo de produção, mas ainda parece manter uma distância significativa entre os processos que ocorrem na academia (universidades, centros de pesquisa, entre outros) e aqueles que ocorrem nas escolas dos níveis básicos de ensino. Por outro lado, também são ainda pouco frequentes os trabalhos em que estejam descritas e apresentadas as formas pelas quais ocorrem tais produções.

Esta temática foi tomada como objeto de pesquisa em tese de doutoramento (MENEZES, 2008), na qual foram analisados os processos de produção de conhecimentos efetuados por professores da educação básica da Rede Estadual de Educação Básica do Estado do Paraná, que a partir de um sistema desenvolvido para este fim específico, denominado de Ambiente Pedagógico Colaborativo, sistematizaram e publicaram na Internet conteúdos pedagógicos relativos às suas disciplinas de atuação.

O presente artigo tem como objetivo discutir o papel das TIC nos processos de formação continuada de professores da educação básica - com vistas à produção de conhecimento - e sua influência na criação e manutenção de comunidades de prática. 


\title{
A sistematização dos saberes docentes
}

Os saberes não devem ser classificados como científicos ou práticos, pois o que muda não são os saberes, e sim a relação que o sujeito mantém com eles, haja vista que

\begin{abstract}
Não há saber que não seja inscrito em relações de saber. O saber é construído em uma história coletiva que é a da mente humana e das atividades do homem e está submetido a processos coletivos de validação, capitalização e transmissão. Como tal, é o produto de relações epistemológicas entre os homens. Não obstante, os homens mantêm com o mundo e entre si (inclusive quando são "homens de ciência") relações que não são apenas epistemológicas. Assim sendo, as relações de saber são necessárias para constituir o saber, mas, também, para apoiá-lo após sua construção: um saber só continua válido enquanto a comunidade científica o reconhecer como tal, enquanto uma sociedade continuar considerando que se trata de um saber que tem valor e merece ser transmitido (CHARLOT, 2000, p. 63).
\end{abstract}

Percebe-se, na literatura, que os conceitos de professor-pesquisador (STENHOUSE, 1998), prático-reflexivo (SCHÖN, 1983) e professor-reflexivo (LISTON; ZEICHNER, 1991; ZEICHNER, 1993) não correspondem a um tipo de professor que, consciente de sua condição de produtor de conhecimentos e da importância e validade desses conhecimentos, dispõe-se a sistematizá-los, torná-los públicos e socializá-los com seus pares de modo a subsidiar as atividades docentes de seus colegas.

Do ponto de vista da socialização, concorda-se com a ideia de que, apesar de todas as críticas que são feitas às formas de organização do trabalho e das dificuldades que são impostas aos sujeitos pelas condições objetivas em que exercem suas atividades docentes, a escola pode ser vista como um espaço propício à colaboração, pois segundo Talavera (1994), os saberes são cotidianamente socializados por professores que compartilham entre si suas ideias e recursos, ou ainda, pedem ajuda a seus colegas para resolverem determinados problemas relacionados à sua prática docente. São estas relações, cotidianas e cordiais, que facilitam a apropriação dos conteúdos de ensino pelos professores.

Assim, para a autora, pode-se considerar que os saberes docentes são difundidos e reconstruídos em variadas situações e interações. A melhor maneira 
de outros professores apropriarem-se desses saberes é a partir do contato direto com suas experiências. No entanto, a natureza dessas interações precisa ser problematizada, uma vez que não se trata de defender a atividade dos professores apenas em trocas de experiência e de reflexões sobre suas próprias práticas, ainda que se considere a importância desse tipo de atividade formativa.

Trata-se, sim, de buscar refletir sobre possibilidades que se abrem, a partir desse debate, de compreender se, e de que forma, os professores podem ser entendidos como produtores de conhecimento. E essa perspectiva remete à necessidade de pensar esta questão a partir do entendimento de que "uma sociologia da experiência incita a que se considere cada indivíduo como um 'intelectual', como um actor capaz de dominar conscientemente, pelo menos em certa medida, a sua relação com o mundo" (DUBET, 1994, p. 107).

É nessa perspectiva que se busca discutir o potencial que as TIC apresentam na condução do professor de educação básica à condição de produtor de conhecimento. Desta forma, entende-se que a utilização efetiva dos recursos tecnológicos independe exclusivamente de sua disponibilização e do mero conhecimento técnico para sua utilização, pois se faz necessária, também, a compreensão da utilização desses recursos a partir de uma perspectiva educacional.

\section{Inclusão digital nas escolas da Rede Estadual de Educação Básica do Estado do Paraná}

Durante o primeiro ano da Gestão 2003/2006 da Secretaria de Estado da Educação do Paraná foi proposta a criação de um programa de inclusão digital que deveria contemplar todas as escolas da Rede Estadual de Educação Básica do Estado do Paraná. Assim, com recursos do BID (Banco Interamericano de Desenvolvimento) e em parceria com o PNUD (Programa das Nações Unidas para o Desenvolvimento), a Secretaria de Estado da Educação do Paraná desenvolveu e implementou o projeto intitulado: "Projeto BRA/03/036 - EDUCAÇÃO BÁSICA E INCLUSÃO DIGITAL NO ESTADO DO PARANÁ".

Seu principal objetivo visava a promoção da inclusão digital em todas as escolas de educação básica da Rede Estadual de Educação Básica do Estado do Paraná. Assim, foram desenvolvidas estratégias que tinham como meta disponibilizar o acesso à Internet a professores, alunos e funcionários da rede pública de educação básica do estado do Paraná, bem como adquirir bens de informática que promovessem este tipo de acesso de forma universalizada (PROGRAMA DAS NAÇÕES UNIDAS PARA O DESENVOLVIMENTO, 2007, p. 4). 
Além de estabelecer um programa de capacitação dos professores, com o intuito de adequar sua linguagem em relação ao hipermeio, este projeto também previa o desenvolvimento de um sistema computadorizado, que contemplasse um modelo colaborativo com vistas à promoção e disseminação das políticas públicas educacionais do Estado do Paraná (PROGRAMA DAS NAÇÕES UNIDAS PARA O DESENVOLVIMENTO, 2007, p. 3).

Financiado com recursos do BID (Banco Interamericano de Desenvolvimento) e com a contrapartida financeira do Governo do Estado do Paraná, este projeto previu investimentos na ordem de cem milhões de reais.

Apesar da amplitude do projeto, este artigo se limitará a analisar os resultados obtidos a partir da utilização de um ambiente computacional na Web - denominado de Ambiente Pedagógico Colaborativo - a partir do qual alguns professores da Rede Estadual de Educação Básica do Estado do Paraná participaram do processo de formalização e publicização de seus saberes docentes, tornando-os públicos na Internet.

\section{Metodologia da investigação}

Esta pesquisa apresenta um cunho qualitativo, que a partir do método indutivo busca demonstrar que a adoção de TIC nos processos de formação continuada de professores da educação básica pode possibilitar a atuação do professor da educação básica enquanto produtor de conhecimento; entretanto, não garante a formação efetiva de comunidades de prática.

A pesquisa documental analisou documentos oficiais que explicitam o objetivo do projeto, bem como dados relacionados aos processos de produção e complementação de conteúdos pedagógicos para a Internet, que estavam disponibilizados no Portal Dia-a-dia Educação (Portal Educacional da Secretaria de Estado da Educação do Paraná).

O caráter explicativo desta pesquisa busca identificar e explicitar fatores que esclareçam o fenômeno da não participação efetiva dos professores da Rede Pública de Educação Básica do Estado do Paraná no Projeto BRA/03/036 EDUCAÇÃO BÁSICA E INCLUSÃO DIGITAL NO ESTADO DO PARANÁ, durante o período de 2003 a 2006.

Para tanto, foram analisados 9.656 publicações efetuadas por professores da educação básica no Ambiente Pedagógico Colaborativo do Portal Dia-a-dia Educação e que apresentavam três peculiaridades: a) todo processo de produção, validação, publicação e complementação dos conteúdos didáticos (denominado 
de OAC - Objeto de Aprendizagem Colaborativa) foi exclusivamente mediado pelas TIC; b) todas as produções foram elaboradas a distância, ou seja, a partir das localidades onde residiam e/ou lecionavam os professores; c) os conteúdos já publicados podiam ser complementados por outros usuários cadastrados no Portal Dia-a-dia Educação, professores ou não.

\section{A internet e as novas formas de relação com os sujeitos e com o conhecimento}

A publicação on-line possui uma capacidade de circulação e difusão incomparavelmente mais poderosa do que a dos materiais impressos, pois independe de impressão e de distribuição física. Como suas atualizações podem ser instantaneamente acessadas pelos usuários, evitam-se constantes reimpressões e redistribuições, reduzindo o custo, aumentando a abrangência de acesso da informação e possibilitando constantes atualizações de conteúdo (MINUTI, 2002, p. 88).

Neste contexto, a Internet possibilita que a autoria fique sujeita a um novo panorama da natureza do discurso, pois a rede mundial de computadores pode promover uma dimensão coletiva e acumulativa no texto, ou seja, após sua publicação, o texto permanece à disposição dos usuários para que possa ser complementado e novamente disponibilizado à comunidade (MINUTI, 2002, p. 101).

Esta premissa pode ser identificada no modelo de colaboração do Ambiente Pedagógico Colaborativo, pois ele objetiva possibilitar

[...] a pesquisa, a consulta e a troca de experiências para subsidiar a prática pedagógica do professor, utilizando-se de um modelo de colaboração, no qual os educadores da Rede Pública de Educação Básica do Estado do Paraná poderão socializar seus conhecimentos, através do acesso aos conteúdos elaborados por seus pares, e ao mesmo tempo divulgar sua produção intelectual (PARANÁ, 2006).

Percebe-se então a intenção de considerar a Internet como um espaço de divulgação e legitimação da produção intelectual dos professores da educação básica. Esta proposta vai ao encontro das proposições de Stenhouse (1998, p. 
38), no que se refere às considerações sobre o fato de que o reconhecimento da pesquisa realizada pelo professor está diretamente relacionada a sua publicização e à finalidade de atender às necessidades locais.

Entretanto, este processo de publicação sofreu uma profunda intervenção estatal, haja vista que a equipe de planejadores do projeto estabeleceu a criação de um grupo destinado a validar os conteúdos enviados para publicação. A seleção e indicação dos validadores dos OAC eram efetuadas pela Secretaria de Estado da Educação do Paraná, que centralizava a atividade e estabelecia as normas e critérios utilizados para validar os OAC enviados pelos professores da Rede Estadual de Educação Básica do Estado do Paraná.

Entende-se que desta forma a Secretaria de Estado da Educação do Paraná buscou garantir a adequação do conteúdo que seria publicado em seu Portal Educacional, assegurando-se de que a conceituação teórica apresentada estaria de acordo com a definição de suas políticas educacionais.

Nesta perspectiva, o Estado passou a assumir a responsabilidade de estruturar e manter as condições de funcionamento dessas comunidades no ciberespaço, bem como manteve o controle sobre os conteúdos disponíveis nestas potenciais comunidades virtuais. Se por um lado a presença do Estado garantiu o aporte de recursos financeiros, a disponibilização de recursos humanos e o estabelecimento de políticas de incentivo que visaram estimular os membros da comunidade a colaborarem com o projeto; por outro lado, esta mesma presença também representou o uso da estrutura para reforçar a política educacional adotada, bem como o cerceamento da liberdade de expressão dos participantes e colaboradores, uma vez que determinou regras para o estabelecimento e funcionamento das comunidades virtuais.

Sendo assim, entende-se que esta intervenção estatal pode ser considerada danosa à constituição de comunidades virtuais, pois o estabelecimento de regras criadas externamente a essas comunidades pode interferir na intenção e disposição das pessoas em participar de debates, bem como em estabelecer teias de relacionamentos no ciberespaço; elementos considerados por Rheingold (1996, p. 18) como essenciais na constituição dessas novas estruturas.

Além disso, a grande capacidade de veiculação de informações em comunidades virtuais deve-se aos contratos sociais mantidos nelas que, ainda que informais, promovem os sujeitos a agentes de software capazes de filtrar e selecionar informações. Tais relações mantêm-se devido à reciprocidade existente entre os membros da comunidade, ou seja, "é necessário dar para poder receber algo em troca" (RHEINGOLD, 1996, p. 78). Nessa perspectiva, a intervenção estatal apresenta-se como um obstáculo à formação de comunidades.

A Tabela 1 é apresentada no intuito de problematizar a atuação dos professores em relação às atividades de colaboração no Ambiente Pedagógico 
Colaborativo. Cabe destacar que os conteúdos didáticos sistematizados pelos professores da Rede Pública de Educação Básica do Estado do Paraná foram sistematizados em um programa de computador denominado OAC (Objeto de Aprendizagem Colaborativa), que são estruturas de dados que agrupam a totalidade dos registros produzidos pelos professores-autores, bem como por aqueles professores que colaboraram a partir da complementação dos conteúdos publicados. Esses registros estão agrupados em estruturas menores, denominadas de "recursos", que podem se repetir inúmeras vezes dentro de um OAC.

Nessa perspectiva, seria correto afirmar que os professores-autores foram responsáveis pela publicação de 9.656 recursos, identificados na Tabela 1 como um tipo de publicação denominada como "completa".

TABELA 1 - PUBLICAÇÕES NO AMBIENTE PEDAGÓGICO COLABORATIVO

\begin{tabular}{|c|c|c|}
\hline Recurso & Tipo & Quantidade \\
\hline Contextualizando & Completa & 445 \\
\hline Curiosidades & Completa & 624 \\
\hline Imagens & Completa & 986 \\
\hline Investigando & Completa & 440 \\
\hline Notícias & Completa & 560 \\
\hline Paraná & Completa & 387 \\
\hline Perspectiva Interdisciplinar & Completa & 456 \\
\hline Propondo Atividades & Completa & 791 \\
\hline Relato & Completa & 504 \\
\hline Sítios & Completa & 1.680 \\
\hline Sons e vídeos & Completa & 876 \\
\hline Sugestão de leitura & Completa & 1.907 \\
\hline Total Geral: & & 9.656 \\
\hline
\end{tabular}

FONTE: Menezes (2008, p. 95).

Ao listar a relação dos OAC publicados no Ambiente Pedagógico Colaborativo, o sistema apresenta o nome e o estabelecimento de ensino ao qual o professor que fez a colaboração está vinculado. A partir dessas informações, pôde-se constatar a existência de 350 colaborações, o que eleva a quantidade de recursos publicados para 10.006. Sendo assim, seria correto afirmar que, no período examinado nesta pesquisa (2003 a 2008), as colaborações representaram apenas 3,5\% dos recursos publicados.

Além deste pequeno índice de colaboração, há um agravante para esta situação: 94,57\% das colaborações, ou seja, 331 das 350 delas foram efetuadas por professores que se encontravam afastados - total ou parcialmente - de sala de 
aula, e que desempenhavam suas atividades em unidades vinculadas à administração central da Secretaria de Estado da Educação do Paraná, a saber: Núcleos Regionais de Educação; Portal Dia-a-dia Educação; Coordenações Regionais de Tecnologia na Educação. Neste artigo, as colaborações desta natureza estão identificadas nos Gráficos 1 e 2 como "Estado".

O Gráfico 1 está organizado por ordem crescente de número de publicações, e representa os $\mathrm{OAC}$ relacionados às disciplinas do Ensino Fundamental. Sua leitura deve ser realizada da seguinte maneira: a parte superior das colunas representa o número total dos $\mathrm{OAC}$ publicados em cada disciplina; a parte intermediária da coluna indica as colaborações efetuadas pelos professores; a parte inferior da coluna representa as colaborações efetuadas pelo Estado. Como um OAC possui 12 recursos, dos quais 11 são passíveis de $n$ colaborações, é possível que se tenha um número de colaborações superior ao número de publicações, como é o caso da disciplina de Arte, apresentada no Gráfico 1, bem como das disciplinas de Educação Física, Arte, Língua Estrangeira e Biologia, apresentadas no Gráfico 2.

Pode-se constatar que das 92 colaborações efetuadas nos OAC relacionados às disciplinas do Ensino Fundamental, o Estado foi responsável por 86 delas, cabendo aos professores que atuam em sala de aula a responsabilidade por apenas 6 das colaborações publicadas. O que significa inferir que a participação do Estado neste nível de ensino correspondeu a 93,47\% das colaborações.

Ao analisar os dados referentes às colaborações efetuadas nos $\mathrm{OAC}$ de disciplinas relacionadas ao Ensino Médio (Gráfico 2), pôde-se constatar que o Estado foi responsável por 245 das 258 colaborações. Isso indica um percentual de $94,96 \%$ de participação do Estado, um percentual próximo daquele apresentado nas disciplinas do Ensino Fundamental (93,47\%). A partir dos dados das colaborações referentes às disciplinas do Ensino Médio, seria correto afirmar que a participação do Estado é 18,86 vezes superior à dos professores que atuam em sala de aula.

Se fosse desconsiderada a participação do Estado nos processos de colaboração, a partir dos dados apresentados, o Ambiente Pedagógico Colaborativo contaria com apenas 19 colaborações, o que representaria apenas $0,19 \%$ do total dos recursos disponíveis. 


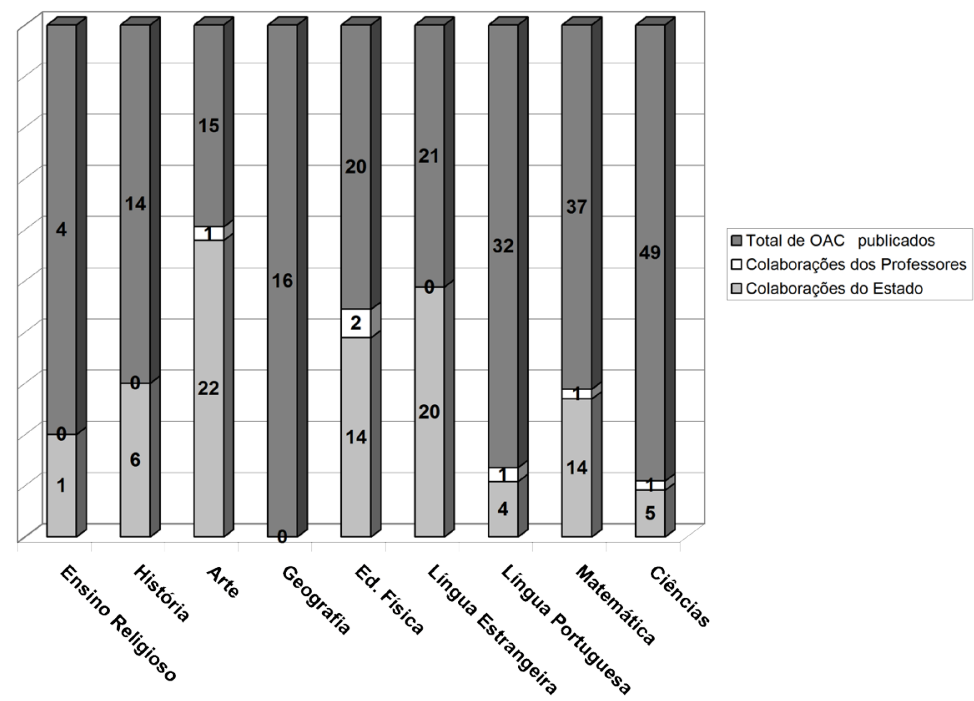

\section{GRÁFICO 1 - COLABORAÇÕES EFETUADAS NOS OAC DE DISCIPLINAS DO ENSINO FUNDAMENTAL}

FONTE: Menezes (2008, p. 97).

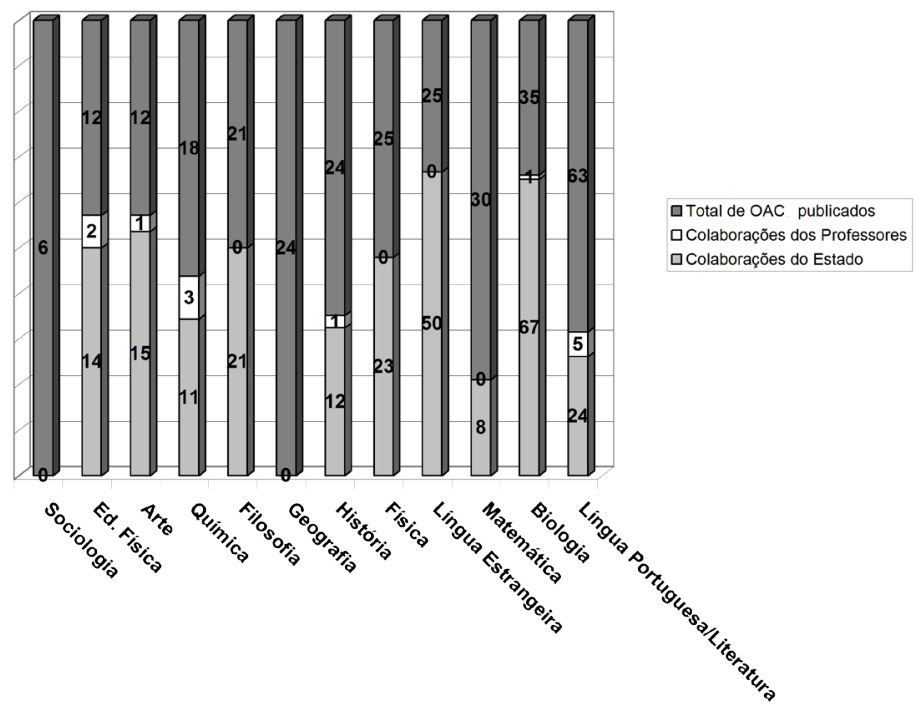

GRÁFICO 2 - COLABORAÇÕES EFETUADAS NOS OAC DE DISCIPLINAS DO ENSINO MÉDIO

FONTE: Menezes (2008, p. 98). 


\section{Análise dos dados}

O processo de produção e publicação de um OAC, em princípio, dispõe de recursos que possibilitam a interação dos professores no intuito de promover a constituição de comunidades de aprendizagem nas seguintes direções: fórum de discussões; colabore.

A produção de um OAC permite que o professor poste uma questão provocadora, a qual é encaminhada ao fórum de discussão da disciplina. Outra possibilidade de o professor se engajar nesta comunidade virtual se dava por meio da complementação dos recursos publicados, como também na elaboração de conteúdos aos recursos não contemplados pelo autor do OAC.

Porém, as colaborações realizadas no intuito de complementar OAC já publicados também eram submetidas aos processos de validação de conteúdos e revisão textual. O autor do OAC não participava, nem era consultado acerca da decisão de incorporar ou não novas informações à sua publicação. Porém, toda colaboração relacionada a seu OAC, ao ser publicada no Ambiente Pedagógico Colaborativo, era automaticamente notificada ao autor por correio eletrônico. A interface gráfica desenvolvida para o Ambiente Pedagógico Colaborativo distingue a produção do autor e as colaborações efetuadas no OAC, separando-as por uma linha horizontal.

Durante o processo de complementação dos OAC publicados no Ambiente Pedagógico Colaborativo, que poderia ser iniciado por qualquer usuário cadastrado junto ao Portal Dia-a-dia Educação, os autores destes OAC em momento algum foram convidados a participar das discussões, ou a opinar sobre a publicação ou não dos novos conteúdos que foram inseridos em sua produção intelectual. Percebe-se então que não foram identificados indícios de "[...] consenso, tomada de decisões democráticas e acção comum", considerados por Carr e Kemmis² (apud GARCÍA, 2005, p. 185) como elementos necessários aos processos de colaboração.

Baseando-se no pensamento de Carr e Kemmis, acredita-se que o procedimento denominado como "colaboração" no Ambiente Pedagógico Colaborativo caracteriza-se mais como uma complementação de recursos publicados, uma vez que, até o momento, não se pôde constatar a configuração de redes que permaneceram atuando na perspectiva do trabalho colaborativo.

Como já foi apresentado anteriormente, pôde-se constatar a pouca adesão dos professores com relação à proposta colaborativa do Portal Dia-a-dia Educação, pois dos 10.006 recursos publicados, apenas 19 são referentes a colaborações

2 CARR, W.; KEMMIS, S. Teoria crítica de la enseñanza. Barcelona: Martinez Roca, 1988. 
efetuadas por professores, ou seja, $0,19 \%$ do total dos registros. No intuito de problematizar este fenômeno, buscou-se na teoria das comunidades de prática (WENGER, 1999) elementos conceituais que pudessem auxiliar na análise do processo colaborativo proposto pelo Ambiente Pedagógico Colaborativo.

Um dos elementos apresentados pelo autor refere-se ao conceito de "identidade na prática”. Pois, segundo Wenger (1999, p. 149), prática e identidade estão intimamente conectadas. Nesta perspectiva, o desenvolvimento de uma prática exige a formação de comunidades nas quais seus membros devem se sentir engajados, bem como se reconhecerem como participantes.

Ao participar efetivamente de comunidades de prática, os membros sentem-se em território familiar, onde os sujeitos são reconhecidos como competentes e sabem como se relacionar uns com os outros. Além disso, também compreendem o como e os porquês das coisas acontecerem. Há um engajamento mútuo, ou seja, os membros sabem como interagir e como trabalhar em conjunto com seus pares. Outro fator importante refere-se ao valor atribuído à competência e conhecimento de cada um, constituindo-se uma identidade que é traduzida na forma de respeito e reconhecimento da comunidade (WENGER, 1999, p. 152).

Sendo assim, pode-se afirmar que o modelo proposto pelo Ambiente Pedagógico Colaborativo não contempla os elementos apresentados acima, pois não há o reconhecimento da competência dos professores, haja vista que a etapa de validação que define se, e como, as colaborações deverão compor os OAC já publicados não previa o envolvimento dos autores. Esta característica de concepção impossibilita a formação de uma identidade dos participantes, estabelecida a partir do reconhecimento da comunidade, pois se subentende que toda colaboração contou apenas com a intervenção dos validadores.

Além disso, entende-se que não há engajamento mútuo, pois não houve nenhum tipo de interação entre o colaborador e o autor do OAC, que é notificado - por meio de mensagem eletrônica emitida automaticamente pelo sistema - sobre as colaborações publicadas em seu OAC.

Com relação à participação dos membros em uma comunidade, Wenger (1999, p. 154) considera que esta pode ser definida por diferentes tipos de trajetórias, a saber: Peripheral trajectories; Inbound trajectories; Insider trajectories; Boundary trajectories; Outbound trajectories. Entretanto, as características do campo de pesquisa direcionam para o conceito denominado como Peripheral trajectories [trajetória periférica].

Apesar de apresentar um pequeno percentual de colaborações, como já exposto anteriormente, deve-se considerar que os OAC foram acessados 27.750 vezes $^{3}$. Deste total, os professores da Rede Estadual de Educação Básica do

3 FONTE: Sistema de Administração do Portal Dia-a-dia Educação - Ref. 05 jan. 2008. 
Estado do Paraná foram responsáveis por 26.744 dos acessos aos OAC (p. 90); o que corresponde a $96,37 \%$ do total de acessos. Esses números indicam a ocorrência de um tipo de trajetória periférica, haja vista que não se caracteriza como uma participação integral, que segundo Wenger (1999, p. 154), pode se tornar significativa o suficiente para contribuir, de alguma forma, na constituição da identidade desses sujeitos.

A elaboração de um OAC, ou a colaboração na complementação de seus recursos, podem ser caracterizadas como um tipo de pertencimento denominado por Wenger (1999, p. 178-181) como "suporte". Segundo o autor, este tipo de pertencimento prevê um tipo de acordo, no qual os participantes concentram suas energias, ações e práticas em um determinado empreendimento, caracterizado neste estudo pela elaboração dos OAC e na colaboração de seus recursos.

Para Wenger (1999, p. 186-187), o suporte exige a habilidade para coordenar perspectivas e ações de forma a direcioná-las a um objetivo comum. Neste contexto, o grande desafio refere-se a direcionar os esforços dos participantes locais para estilos e discursos mais amplos, de modo a conduzi-los a investir seu tempo e energia em determinada atividade. Este tipo de pertencimento apresenta as seguintes características: investir energia em um caminho direcionado e criar um foco para coordenar este investimento de energia; negociar perspectivas, buscando um nível de aceitação comum; impor uma visão utilizando o poder e a autoridade; convencer, inspirar e unificar; definir uma ampla visão e aspiração propondo histórias de identidade; arquitetar procedimentos, quantificações e estruturas de controle que possam ser utilizadas fora dos limites físicos da organização.

Tais elementos podem ser identificados na proposta do Ambiente Pedagógico Colaborativo, pois sua rígida estrutura de entrada de dados direciona o professor a apresentar informações a partir de um modelo preestabelecido, adotando a pontuação para as publicações dos OAC como uma forma de compensar o investimento de energia desses professores.

O processo de validação, caracterizado como um sistema capaz de registrar a produção dos professores, bem como os comentários dos validadores sobre essas produções, é caracterizado como um meio de negociação de significados, empregado com a finalidade de buscar a aceitação comum para possíveis alterações de conteúdos e publicação dos OAC.

Apesar da existência de um espaço para o diálogo entre o professor e o validador, cabe a este último, em casos de controvérsia em relação aos comentários e/ou críticas, o recurso da autoridade. Pois sem a aprovação do validador não é efetivada a publicação do OAC.

Entende-se que esta proposta contempla a definição de procedimentos, quantificações e estruturas de controle que possam ser utilizadas fora dos limi- 
tes físicos da organização, haja vista que seu desenvolvimento está pautado na utilização de um sistema informatizado capaz de possibilitar que uma equipe centralizada na Secretaria de Estado da Educação do Paraná, sediada no município de Curitiba, possa: avaliar; comentar; revisar; publicar e excluir os OAC e as colaborações.

Sendo assim, pode-se afirmar que a partir do exposto, esta proposta constitui-se na formação de uma comunidade de prática que possui processos de formação de identidade e aprendizado pautados no conceito de "suporte" (WENGER, 1999).

Entretanto, também seria correto afirmar que o Ambiente Pedagógico Colaborativo pode ser considerado como uma estrutura denominada como "redes da prática" (BROWN; DUGUID, 2001, p. 125), haja vista que sua proposta contempla as seguintes características: possibilita que a informação trafegue em alta velocidade e que atinja um grande número de pessoas, sem com isso perder suas características originais; que possibilite a conexão de pessoas a outras que trabalham em práticas similares, mas que dificilmente teriam oportunidade de se conhecerem pessoalmente.

\section{Considerações finais}

Apesar das limitações aqui apresentadas, entende-se que o Ambiente Pedagógico Colaborativo representa um avanço significativo na utilização das TIC no contexto educacional, pois permitiu que alguns professores da Rede Estadual de Educação Básica do Estado do Paraná pudessem utilizar a Internet para registrarem e socializarem suas práticas pedagógicas, e também suas experiências e conhecimentos relacionados às disciplinas que lecionam.

No intuito de estruturar e manter as condições de funcionamento dessas comunidades no ciberespaço, o Estado definiu ações de controle sobre os conteúdos disponíveis nessas comunidades virtuais, fator que, conforme demonstrado, foi o principal responsável por dificultar o estabelecimento de relações pessoais e profissionais entre os participantes.

Entende-se que o controle adotado pela Secretaria de Estado da Educação do Paraná caracterizou um modelo de intervenção fiscalizadora com relação aos conteúdos que foram veiculados nos sistemas por ele geridos, inviabilizando a livre circulação de informações e, consequentemente, enfraquecendo o estabelecimento de vínculos sociais mantidos entre os membros das comunidades - os professores. 
Ainda que se possa questionar se os dados numéricos são significativos para qualificar positivamente os resultados, entende-se que a abertura desse espaço para compartilhar conhecimentos relacionados ao ensino está efetivamente realizada.

Pôde-se constatar que durante o processo de produção dos OAC, os professores foram estimulados a se colocarem como sujeitos que produzem conteúdos, mas que também se encontravam em processo de formação em serviço, já que sua produção recebeu críticas e orientações da equipe de validadores instituída pela Secretaria de Estado da Educação do Paraná. Nessa perspectiva, o Ambiente Pedagógico Colaborativo se caracterizou por estabelecer ações que visavam à formação continuada a distância para os professores da Rede Estadual de Educação Básica do Estado do Paraná.

Ainda há questões que necessitam ser pesquisadas do ponto de vista da formação de redes, por exemplo: como os professores produtores de OAC entendem sua participação nesse processo? Que tipo de pertencimento foi construído, na perspectiva desses sujeitos?

\section{REFERÊNCIAS}

BROWN, John Seely; DUGUID, Paul. A vida social da informação. São Paulo: MAKRON Books, 2001.

CHARLOT, Bernard. Da relação com o saber: elementos para uma teoria. Porto Alegre: Artes Médicas Sul, 2000.

DUBET, François. Sociologia da experiência. Lisboa: Instituto Piaget, 1994.

GARCÍA, Carlos Marcelo. Formação de professores: para uma mudança educativa. Porto: Porto Editora, 2005.

LISTON, Daniel P.; ZEICHNER, Kenneth M. Teacher education and the social conditions of schooling. New York: Routledge, 1991.

MENEZES, Glauco Gomes de. Ambiente pedagógico colaborativo do portal dia-a-dia educação: análise do modelo didático-tecnológico. Tese (Doutorado em Educação) - Programa de Pós-Graduação em Educação, Universidade Federal do Paraná, Curitiba, 2008.

MINUTI, Rolando. Internet et lê métier d'historien: réflexions sur les incertitudes dúne mutation. Paris: Presses Universitaires de France, 2002.

PARANÁ. Secretaria de Estado da Educação. Portal Dia-a-dia Educação. O que ele possibilita? Disponível em: <http://www.diaadiaeducacao.pr.gov.br/portals/apc/oque/ apc_saiba.php?PHPSESSID=2006112021261767\#>. Acesso em: 20/05/2006. 
POLSANI, Pithamber R. The use and abuse of reusable learning objects. Disponível em: <www.dei.inf.uc3m.es/ebecdl2002/papers/polsaniLO.doc>. Acesso em: 21/12/2007.

PROGRAMA DAS NAÇÕES UNIDAS PARA O DESENVOLVIMENTO. Projeto BRA/03/036 educação básica e inclusão digital no estado do Paraná. Disponível em: $<$ http://www.pnud.org.br/arquivos/arqui1084291939.zip>. Acesso em: 10/01/2007.

RHEINGOLD, Howard. A comunidade virtual. Lisboa: Gradiva, 1996.

SACRISTÁN, J. Gimeno; GÓMEZ, A. I. Pérez. Compreender e transformar o ensino. 4. ed. Porto Alegre: Artmed, 1998.

SCHÖN, Donald. The reflective pratitioner: how professionals think in action. New York: Basic Books, Inc., 1983.

Educando o profissional reflexivo: um novo design para o ensino e a aprendizagem. Porto Alegre: Artmed, 2000.

STENHOUSE, Lawrence. La investigación como base de la enseñanza. Madrid: Ediciones Morata S.L., 1998.

TALAVERA, Maria Luisa. Como se inician los maestros en su profesión. La Paz: CEBIAE, 1994.

WENGER, Etienne. Communities of practice: learning, meaning and identity. Cambridge: Cambridge University Press, 1999.

ZEICHNER, Kenneth. A formação reflexiva de professores: ideias e práticas. Lisboa: Educa.Professores, 1993.

Texto recebido em 26 de novembro de 2012.

Texto aprovado em 07 de outubro de 2013. 